\title{
Effectivity battle between C-MAC and McGrath $®$ video laryngoscope in a patient with general anesthesia at Sanglah Hospital: A pilot study
}

Jhoni Pardomuan Pasaribu' Tjokorda Gde Agung Senapathi ${ }^{2}$ Pontisomaya Parami ${ }^{3}$

'Resident, Department of Anesthesiology, Pain Management, and Intensive Care, Udayana University, Sanglah General Hospital, Denpasar-Bali, Indonesia ${ }^{2}$ Associate Professor, Department of Anesthesiology, Pain Management, and Intensive Care, Udayana University, Sanglah General Hospital, Denpasar-Bali, Indonesia ${ }^{3}$ Lecturer Department of Anesthesiology, Pain Management, and Intensive Care, Udayana University, Sanglah General Hospital, Denpasar-Bali, Indonesia

\section{Cite this article:}

Pasaribu JP, Senapathi TGA, Parami P. Effectivity battle between C-MAC and McGrath ${ }^{\circledR}$ video laryngoscope in a patient with general anesthesia at Sanglah Hospital: A pilot study. Neurologico Spinale Medico Chirurgico. 2021.4(2):47-50. DOI: I0.36444/nsmc.v4i2.16I

\section{Corresponding author:}

Jhoni Pardomuan Pasaribu

Resident, Department of Anesthesiology, Pain Management, and Intensive Care, Udayana University, Sanglah General Hospital, DenpasarBali, Indonesia jopbius2017@gmail.com

\begin{abstract}
Background: Intubation is a common essential procedure to maintain the airway during general anesthesia. Various video laryngoscopes (VL) on the market today assist anesthesiologists in improving intubation success rates and also in complicated airway cases. There are two types of VL found in our institution, which are C-MAC and McGrath ${ }^{\circledR}$. Each of them has its pros and cons, which withdrawn our curiosity to compare their effectiveness.
\end{abstract}

Methods: A pilot study was conducted in our center; we included all patients undergoing general anesthesia with physical status ASA I-III and consent to the study and divide them into two groups, C-MAC and McGrath®. We compare C-MAC and McGrath ${ }^{\circledR}$ VL effectiveness in terms of time for intubation, ease of intubation, total attempt, failure to intubate, Cormack Lehane degree, POGO Score, and hemodynamic stability.

Results: A total of 20 patients were intubated with two different VL, ten patients for each group. Both VLs accommodate ease of intubation, and overall first attempt successful intubation, though C-MAC showed better laryngeal and glottic visualization, shorter tracheal intubation times, and less hemodynamic change.

Conclusion: C-MAC give better result in laryngeal and glottic visualization, shorter tracheal intubation times, and less hemodynamic change.

Keywords: Video laryngoscope, C-MAC, McGrath®, Intubation, Cormack Lehane degree, POGO score

\section{Introduction}

Intubation is the quintessential skill to master for an anesthetist. Besides its importance as airway management for critical or sedated patients, the ability to achieve smooth and successful intubation gives a tremendous self-satisfaction pride. The standard conventional laryngoscope is the most common tool provided in Indonesia healthcare facility. However, the use of a more modern laryngoscope is crucial in a patient with a difficult airway. Today, in this fast-growing digital era, many advanced medical devices were made to ease their operator, giving a better performance to increase patients' well-being. 
Since the early $21 \mathrm{st}$ century, VL was commercially introduced in the market, and more types and brands with their different specifications were available in this world. Our centre has two types of VL which are C-MAC and McGrath®. C-MAC VL is manufacture by Karl Storz, Tuttlingen, Germany ${ }^{1}$, while McGrath ${ }^{\circledR}$ is manufactured by McGRATH-MAC@; Aircraft Medical Ltd., Edinburgh, UK. ${ }^{2}$ Our anesthesiologist provided a variety of opinions on the advantages and disadvantages of each device, while in several prior literatures showed a various result. Some demonstrated C-MAC gives more benefit and ease to intubate, and some said McGrath®. It was stated that C-MAC's blade is similar to standard conventional Macintosh laryngoscope, which is more familiar to its user, while McGrath ${ }^{\circledR}$ is lighter and more compact, around 200 gram, and its screen position nearby the blade, which gives better hand-eye coordination. ${ }^{2-4}$ In comparison to McGrath ${ }^{\circledR}$, C-MAC VL had a faster intubation time, fewer attempts, and better hemodynamic stability, especially in obese patients and those with a Mallampaty score of 3 or above. ${ }^{3,5}$ McGrath ${ }^{\circledR}$ was the chosen device by several users in prior studies due to its lightweight, ergonomic handle, and its screen position, which provide good hand-eye coordination. ${ }^{4}$ Nonetheless, McGrath ${ }^{\circledR}$ and C-MAC VL devices have a high first-attempt success rate, $98 \%$, and $95 \%$, respectively, in patients with limited cervical mobility and mouth opening. ${ }^{6}$

Even though both devices have diverse results, but all prior studies agreed that the use of VL (including both devices) gives better intubation results, in terms of glottic view, especially in patients with difficult airway risks. ${ }^{5}$ We decided to compare C-MAC and McGrath ${ }^{\circledR}$ VL effectiveness in terms of time to intubation, ease of intubation, total attempt, failure to intubate, Cormack Lehane degree, POGO Score, and hemodynamic stability in patients undergoing general anaesthesia because of the disparity in prior literatures and differing opinions from our anaesthetists on both devices.

\section{Methods}

We present 20 cases separated into two groups: group 1 has ten people intubated with C-MAC VL, while group 2 has ten instances intubated with $\mathrm{McGrath} \circledast$. All subjects were undergoing general anaesthesia and has consent to join this study. The inclusion criteria were as follow: all elective patient undergoing non-maxillofacial trauma surgery, with general anaesthesia, physical status ASA I-III, age between 18 to 65 years old, and body mass index $<35 \mathrm{Kg} / \mathrm{m}^{2}$. A patient who didn't consent to this study was excluded, along with cervical instability, teeth anomaly (prominent upper incisors or canines, missing teeth), thyromental distance $<6 \mathrm{~cm}$, inter incisor distance $<3,5 \mathrm{~cm}$, and history of difficult intubation. Drop out criteria were difficult intubation that failed to intubate, more than three attempts, or intubation for more than 10 minutes. $3,7,8$

C-MAC and McGrath ${ }^{\circledR}$ VL effectiveness were evaluated in terms of time to intubation, ease of intubation, total attempt, failure to intubate, Cormack Lehane degree, POGO Score, and hemodynamic stability. Time to intubation is measured since the devices were handpicked until successfully placing the endotracheal tube was beyond the vocal cord, evidenced by measuring EtCO2 Capnograph. ${ }^{5,6}$ The ease of intubation was measured by asking the operator how easy the intubation was done. Intubation at level 1 is effortless, level 2 requires some external manipulation, and level 3 is difficult and leads to intubation failure. ${ }^{5}$ Fail to intubate is defined as the inability to intubate after three attempts. Cormack Lehan degree was evaluated to visualize laryngeal view during laryngoscopy. Grade 1 is full glottic opening, grade 2 partial glottic opening, grade 3 epiglottis view only. ${ }^{9}$ POGO Score represents the percentage of glottic opening seen during laryngoscopy. Grade 1 full glottic opening 75-100\%, grade 2 glottic opening 50-75\%, grade 3 glottic opening $25-50 \%$, and grade 4 glottic opening $0-25 \%$. $^{9}$

Hemodynamic, heart rate (HR), mean arterial pressure (MAP), respiratory rate (RR), $\mathrm{SpO}$, was recorded at $\mathrm{T} 0$ : before intubation, T1: at $1^{\text {st }}$ minute after intubation, T2: the second minute, T3: the third minute, T4: the fourth minute, T5: the fifth minute after intubation. A stable hemodynamic is defined as less than $20 \%$ hemodynamic fluctuation from $\mathrm{T} 0 .^{5}$

\section{Results}

The summary of all 20 patients in this study can be seen in table 1 for group 1 subjects and table 2 for group 2 subjects.

\section{Discussion}

C-MAC group resulted in a better larynx and glottic visualization, $100 \%$ successful intubation, no intubation failure, and a more hemodynamically stable. Time to intubate was also shorter in the C-MAC group. This result is accordant to prior studies that revealed the use of C-MAC enhances laryngeal and glottic view, shorter tracheal intubation times, and less hemodynamic change. ${ }^{3,5,10,11}$

We traced back the patient who experience failure to intubate in the McGrath ${ }^{\circledR}$ group. This failure is believed caused by the poor glottic view due to hypopharynx mass, which explains the level 3 difficulty of intubation. Furthermore, all patients in the McGrath ${ }^{\circledR}$ gro- 
Table 1. Summary of all CMAC group patients

\section{Patients}

\begin{tabular}{|c|c|c|c|c|c|c|c|c|c|c|}
\hline Variables & 1 & 2 & 3 & 4 & 5 & 6 & 7 & 8 & 9 & 10 \\
\hline Sex & $\mathrm{F}$ & $\mathrm{F}$ & M & M & M & M & $\mathrm{F}$ & M & $\mathrm{F}$ & $\mathrm{F}$ \\
\hline Age & 34 & 61 & 26 & 73 & 40 & 55 & 42 & 29 & 51 & 73 \\
\hline BMI & 24,3 & 23,4 & 25,9 & 31 & 24,4 & 17,9 & 20,8 & 19,5 & 23,5 & 17,7 \\
\hline ASA & 1 & 1 & 1 & 1 & 2 & 1 & 2 & 1 & 2 & 1 \\
\hline Lemon score & 0 & 0 & 0 & 0 & 2 & 0 & 1 & 1 & 0 & 0 \\
\hline Time (Sec) & 8 & 180 & 13 & 9 & 11 & 130 & 14 & 12 & 8 & 5 \\
\hline Ease & 1 & 1 & 1 & 1 & 2 & 1 & 1 & 1 & 1 & 1 \\
\hline Attempt & 1 & 1 & 1 & 1 & 1 & 1 & 1 & 1 & 1 & 1 \\
\hline Failure & 0 & 0 & 0 & 0 & 0 & 0 & 0 & 0 & 0 & 0 \\
\hline $\begin{array}{l}\text { Cormack- } \\
\text { Lehane degree }\end{array}$ & I & II & II & II & II & I & IV & II & I & II \\
\hline $\begin{array}{l}\text { POGO score } \\
\% / \text { grade }\end{array}$ & $90 / 1$ & $100 / 1$ & $100 / 1$ & $100 / 1$ & $80 / 1$ & $100 / 1$ & $90 / 1$ & $80 / 1$ & $90 / 1$ & $100 / 1$ \\
\hline Haemodynamic & stable & stable & stable & stable & stable & stable & change & stable & stable & stable \\
\hline
\end{tabular}

Table 2. Summary of all McGrath ${ }^{\circledR}$ group patients

\begin{tabular}{lllllllllll}
\hline & \multicolumn{7}{c}{ Patients } \\
\hline Variables & 1 & 2 & 3 & 4 & 5 & 6 & 7 & 8 & 9 & 10 \\
\hline Sex & M & F & M & M & M & F & F & F & F & M \\
\hline Age & 47 & 42 & 49 & 26 & 35 & 61 & 30 & 15 & 48 & 55 \\
\hline BMI & 20,2 & 28,7 & 20,3 & 21,48 & 23,2 & 29,3 & 21,36 & 19,5 & 15 & 22,2 \\
\hline ASA & 2 & 1 & 2 & 1 & 1 & 1 & 1 & 1 & 1 & 1 \\
\hline Lemon score & 1 & 0 & 0 & 1 & 0 & 0 & 3 & 1 & 0 & 2 \\
\hline Time (Sec) & 560 & 20 & 20 & 20 & 35 & 32 & 60 & 35 & 30 & 30 \\
\hline Ease & 3 & 1 & 1 & 1 & 1 & 1 & 1 & 1 & 1 & 1 \\
\hline Attempt & 3 & 1 & 1 & 1 & 1 & 1 & 1 & 1 & 1 & 1 \\
\hline Failure & 1 & 0 & 0 & 0 & 0 & 0 & 0 & 0 & 0 & 0 \\
\hline Cormack-Lehane & III & II & II & II & II & I & II & I & III & II \\
degree & stable & stable & change & stable & stable & stable & stable & stable & stable & change \\
\hline POGO score & $75 / 2$ & $82 / 1$ & $75 / 2$ & $80,6 / 1$ & $70 / 2$ & $100 / 1$ & $80 / 1$ & $100 / 1$ & $80 / 1$ & $80 / 1$ \\
\hline Haemodynamic: & & & & & & & & & \\
\hline
\end{tabular}


up had successful intubation at the first attempt.

C-MAC's greater achievement compared to McGrath ${ }^{\circledR}$ is assumed due to the familiarity of the standard Macintosh blade and higher screen resolution. ${ }^{1,11,12}$ From the technical aspect, C-MAC has more high technology components, even though the size and the weight of the device are way greater than McGrath ${ }^{\circledR} .^{1,12}$

Indeed, C-MAC is less portable than McGrath $®$, but because this study was conducted in our central operating theatre, the portability issue has no advantage in this setting. McGrath ${ }^{\circledR}$ is a pocket intubation tool, which didn't provide any additional benefit in a central operating theatre, which has been equipped with complete equipment and a specific setting for anesthesia and surgery. The use of McGrath ${ }^{\circledR}$ outside the operating room perhaps gives a more beneficial result.

\section{Conclusion}

This preliminary study revealed that both C-MAC and McGrath ${ }^{\circledR}$ both give ease of intubation, mostly level 1, and overall first attempt successful intubation. Yet, C-MAC provides better achievements in several parameters evaluated in this study, such as laryngeal and glottic view, shorter tracheal intubation times, and less hemodynamic change. Further experimental analysis study is recommended to assess both device effectivity statistically.

\section{Acknowledgment}

The authors report no conflict of interest. It is not being considered for publication, nor has it been published in whole or in part elsewhere. All authors have contributed intellectually to the work, participated in the work to the extent that he can defend the contents and have read the manuscript before its submission for publication. It has been submitted with the full knowledge and approval of the institution.

\section{References}

1. Storz K. Instruction for use C-MAC (® video laryngoscope 8401xxx, Electronic Module 8401 / 8402 X , C-MAC ® PM 8401 XD. Germany: KARL STORZ SE \& Co.KG. 2019.

2. Aircraft-Medical. McGrath operator's manual. United Kingdom: Aircraft Medical Ltd. 2017.
3. Ng I, Hill AL, Williams DL, et al. Randomized controlled trial comparing the McGrath videolaryngoscope with the C-MAC videolaryngoscope in intubating adult patients with potential difficult airways. British Journal of Anaesthesia. 2012;109:439-443. DOI: 10.1093/bja/aes145

4. Shin M, Bai SJ, Lee KY, et al. Comparing McGRATH® MAC, C-MAC $®$, and Macintosh laryngoscopes operated by medical students: A randomized, crossover, manikin study. BioMed Research International. 2016. DOI: $10.1155 / 2016 / 8943931$

5. Akbas S, Ozkan AS, Karaaslan E. A Comparison of McGrath MAC versus C-MAC videolaryngoscopes in morbidly obese patients undergoing bariatric surgery: A randomized, controlled clinical trial. Bariatric Surgical Practice and Patient Care. 2019;14:25-33. DOI: 10.1089/bari.2018.0052

6. Kleine-Brueggeney $\mathrm{M}$, Greif $\mathrm{R}$, Schoettker $\mathrm{P}$, et al. Evaluation of six videolaryngoscopes in 720 patients with a simulated difficult airway: A multicentre randomized controlled trial. British Journal of Anaesthesia. 2016;116:670-679. DOI: 10.1093/bja/aew058

7. Gupta S, Sharma KRR, Jain D. Airway assessment: Predictors of difficult airway. Indian $J$ Anaesth. 2005;49:257-262. Available at: https://www.ijaweb.org/article.asp?issn=0019-

5049 ; year $=2005 ;$ volume $=49 ;$ issue $=4 ;$ spage $=257$; page $=257$; aulast $=$ Gupta; type $=2$

8. Maassen $\mathrm{R}$, Lee $\mathrm{R}$, Hermans $\mathrm{B}$, et al. A comparison of three videolaryngoscopes: The macintosh laryngoscope blade reduces, but does not replace, routine stylet use for intubation in morbidly obese patients. Anesthesia and Analgesia. 2009;109:1560-1565. DOI: 10.1213/ANE.0b013e3181b7303a

9. Levitan RM, Ochroch EA, Kush S, et al. Assessment of airway visualization: Validation of the percentage of glottic opening (POGO) scale. Academic Emergency Medicine. 1998;5:919-923. DOI: 10.1111/j.15532712.1998.tb02823.x

10. Kilicaslan A, Topal A, Tavlan A, et al. Effectiveness of the C-MAC video laryngoscope in the management of unexpected failed intubations. Brazilian Journal of Anesthesiology. 2014;64:62-65. DOI: 10.1016/j.bjane.2013.03.001

11. Xue FS, Li HX, Liu YY, et al. Current evidence for the use of C-MAC videolaryngoscope in adult airway management: A review of the literature. Therapeutics and Clinical Risk Management. 2017;13:831-841. DOI: 10.2147/TCRM.S136221

12. Cierniak M, Timler D, Wieczorek A, et al. The comparison of the technical parameters in endotracheal intubation devices: The Cmac, the Vividtrac, the McGrath Mac and the Kingvision. Journal of Clinical Monitoring and Computing. 2016;30:379-387. DOI: 10.1007/s10877-015-9727-2 